\title{
ACCEPTANCE OF LOW VISION AIDS IN VISUALLY IMPAIRED PATIENTS ATTENDING TO TERTIARY EYE HOSPITAL, NEPAL
}

\author{
Adhikari $P R^{1^{*}}$, Khanal $M^{2}$, Chaudhary $N^{3}$,Chaudhry $M^{4}$, Anwar $A^{5}$, Karn $R R^{6}$
}

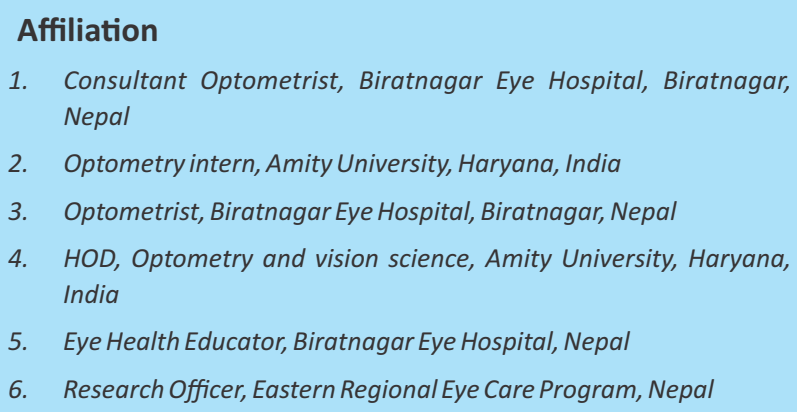

1. Consultant Optometrist, Biratnagar Eye Hospital, Biratnagar, Nepal

2. Optometry intern, Amity University, Haryana, India

3. Optometrist, Biratnagar Eye Hospital, Biratnagar, Nepal

4. HOD, Optometry and vision science, Amity University, Haryana, India

5. Eye Health Educator, Biratnagar Eye Hospital, Nepal

6. Research Officer, Eastern Regional Eye Care Program, Nepal

\section{ARTICLE INFO}

Received : 15 October, 2019

Accepted : 05 March, 2020

Published : 30 June, 2020

(C) Authors retain copyright and grant the journal right of first publication with the work simultaneously licensed under Creative Commons Attribution License CC - BY 4.0 that allows others to share the work with an acknowledgment of the work's authorship and initial publication in this journal.

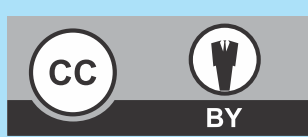

ORA 154

\section{DOI:https://doi.org/10.3126/bjhs.v5i1.29611}

\author{
* Corresponding Author \\ Mr. Pankaj Ray Adhikari \\ Consultant Optometrist \\ Biratnagar Eye Hospital, Biratnagar, Nepal \\ Email: pankajaiims@gmail.com \\ ORCID ID: https://orcid.org/0000-0002-4246-2153
}

\section{Citation}

Adhikari PR, Khanal M, Chaudhary N,Chaudhry M, Anwar A, Karn RR. Acceptance of Low Vision Aids in Visually Impaired Patients Attending to Tertiary Eye Hospital, Nepal. BJHS 2020;5(1)11: 907-910.

\section{ABSTRACT}

\section{Introduction}

Vision impairment is the degree of reduction in vision that makes a remarkable effect on personality, intelligence, social, mental and economic factors of individuals.

\section{Objective}

To analyze the acceptance of low vision aids with their respective occupations and needs in visually impaired patients attending to Tertiary Eye Hospital.

\section{Methodology}

A cross-sectional study was done at the low vision clinic of Biratnagar Eye Hospital (BEH), Biratnagar, Nepal from January to March 2018. During the study period, a total of 51 visually impaired patients were included for the study who were eligible and willing to participate.

\section{Result}

The most common age group visited to low vision clinic were up to 20 years (43\%). Males comprised a maximum study population of $(88 \%)$ and most of them were from the neighboring country India (96\%). The most common disease-causing low vision was Retinal Diseases (41\%). Among all occupations, students accepted more optical low vision aids for both distance(31.5\%) and near (47\%). The most common demand was reading and writing (86\%). At distance, the telescope was prescribed to $(65 \%)$ and at near, spectacle magnifiers were prescribed to $(72 \%)$.

\section{Conclusion}

There is more acceptance of the low vision aids among the students for both distance and near work compare to other occupation. The low vision device should be prescribed concerning the education, occupation, and needs of the patients.

\section{KEYWORDS}

eye hospital, low vision aids, occupation, Nepal 


\section{INTRODUCTION}

A person with low vision is the one who has impairment of visual function even after treatment and/or standard refractive correction, and has visual acuity of less than $6 / 18$ to light perception or a visual field of less than 20 degree from the point of fixation but who uses or is potentially able to use vision for the planning and/or execution of task. ${ }^{1}$ In the scenario of the world, more than 253 million people in the world are visually impaired, of whom 36 million are blind, and 217 million people require low vision care and are likely to get benefit from that. ${ }^{2}$ In the context of Nepal, although no nationwide survey has been conducted on the prevalence of low vision in Nepal, it has been estimated that the prevalence of low vision is (1\%) of the total population. ${ }^{3}$ The occurrence of low vision covers a wide area of ocular pathologies and varies from patient to patient and so does their visual demand concerning the cause of their problem. Low vision patients have difficulty in living quality of life. ${ }^{4}$ Living with low vision is difficult and is associated with decreased functional status, decreased self-esteem and emotionally distracted and isolated. ${ }^{5}$ Ultimately there is a big loss in the economy and happiness of the family. Not only that but children are deprived of education and adults lose their position and self-esteem to work properly. To overcome the problem, certain low vision aids help to live a better life for low vision patients. ${ }^{6}$ Low vision aids which range from simple optical magnifier to high magnification video magnifiers help to improve the residual vision by providing appropriate power and special training to use them. ${ }^{7}$ Optical intervention helps to improve the residual vision of the students of an integrated school. ${ }^{8}$ So the low vision aids help patients to make use of remaining vision to the maximum extent so that they utilize residual vision effectively to meet their daily requirements. ${ }^{9}$ Studies shows that low vision aids can be prescribed in various ocular diseases depending upon occupation, age, and needs of the patient. But though their vision is improved with low visual aids they do not want to buy the aids. Occupation therapy practitioners who provide intervention for adults with low vision need to understand challenges with occupational performances from the individual perspective to implement effective treatment. ${ }^{10}$ The study was aimed to analyze the acceptance of low vision aids with their respective occupation and needs in visually impaired patients which help them to lead their life better way.

\section{METHODOLOGY}

A cross-sectional study was done at the low vision clinic of Biratnagar Eye Hospital (BEH), Biratnagar, Nepal from January to March 2018. During the study period, a total of 127 patients with low vision were referred for low vision assessment in low vision clinics from different subspecialty clinics of BEH. Total 51 visually impaired patients were included for the study who were willing to participate and the best-corrected visual acuity $<6 / 18$ to Perception of light $(\mathrm{PL})$ were included and visual acuity having No Perception of Light (NPL) and children less than 5 years were excluded.
Written consent was taken and comprehensive low vision assessment was done as per the guidelines by optometrists trained in low vision care. ${ }^{11}$ Optical low vision aids such as handheld monocular telescope of different magnification trial was done for distance and spectacle magnifier, handheld magnifier, stand magnifier, dome magnifier, pocket magnifier for near according to visual demands and occupation followed by non-optical devices. Proper counseling was given to use low vision aids if there was improvement in distance as well as near visual acuity. Mobile recording was done to know the reason for acceptance of low vision aids and variables such as demographic data, uncorrected and best-corrected visual acuity, visual demand, the reason for the acceptance of low vision devices was recorded and data was collected by assessment form and mobile recorder and entered in excel sheet. Data analysis was done using SPSS-17 version (Statistical Package for the Social Science). Statistical analysis was measured by using pair T-test and $p$-value $<0.05$ was considered statistically significant. Ethical clearance was taken from the Institutional Review Committee (IRC) of Biratnagar Eye Hospital.

\section{RESULTS}

Among 51 low vision patients, (88\%) were male, most of them were from the neighboring country India (96\%). The most common age group visiting low vision clinic was of age group up to 20 (43\%), followed by the age group of $21-50$ (31.5\%), and above 51(25.5\%). Among all the patients most of them had completed their education up to primary level (39\%) followed by secondary level (35\%), higher secondary and above was (18\%) (Table 1)

Table 1: Demographic distribution

\begin{tabular}{|l|c|}
\hline Gender & Frequency (\%) \\
\hline Male & $45(88)$ \\
\hline Female & $6(12)$ \\
\hline Nationality & $49(96)$ \\
\hline India & $2(4)$ \\
\hline Nepal & \\
\hline Age Group(yr) & $22(43)$ \\
\hline Up to 20 & $16(31.5)$ \\
\hline 21 to 50 & $13(25.5)$ \\
\hline Above 51 & \\
\hline Education & $4(8)$ \\
\hline Illiterate & $20(39)$ \\
\hline Primary & $18(35)$ \\
\hline Secondary & $9(18)$ \\
\hline $\begin{array}{l}\text { Higher secondary } \\
\text { and above }\end{array}$ & $\mathbf{5 1}$ \\
\hline Total & \\
\hline
\end{tabular}


The Major Causes of low vision was Retinal diseases (41\%) followed by high refractive error (14\%) Glaucoma (12\%), Nystagmus (12\%) and Others (21\%).(Table 2)

Table 2: Different types of ocular pathologies associated with visual impairment.

\begin{tabular}{|l|c|}
\hline Ocular pathologies & Frequency (\%) \\
\hline Retinal diseases & $21(41)$ \\
\hline Refractive errors & $7(14)$ \\
\hline Glaucoma & $6(12)$ \\
\hline Nystagmus & $6(12)$ \\
\hline $\begin{array}{l}\text { Others(Albinism, Amblyopia, } \\
\text { Adherent leukoma, } \\
\text { Microphthalmos) }\end{array}$ \\
\hline Total & $11(21)$ \\
\hline
\end{tabular}

The primary visual demand was taken based on which the optical devices were tried. The most common demand was reading and writing (86\%) followed by counting money (8\%) and other visual demands were tailoring work, art work and recognizing peoples face (6\%) (Figure 1 )

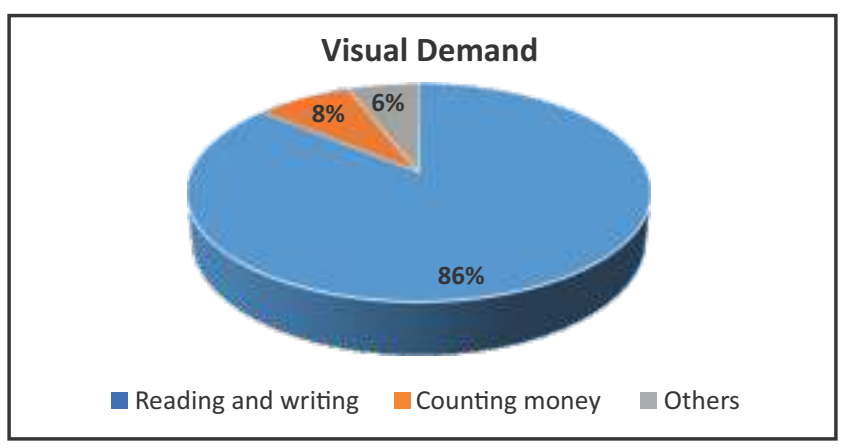

Figure 1: Visual Demand

There was improvement in distance vision with low vision aids which was highly significant and also in near visual acuity after using magnification which was not statistically significant. (Table 3)

Table: 3 Uncorrected Visual Acuity (UCVA) and Best corrected Visual acuity (BCVA) for Distance and Near

\begin{tabular}{|c|c|c|c|}
\hline Distance Visual acuity in log MAR & $\begin{array}{c}\text { UCVA } \\
\mathrm{n}(\%)\end{array}$ & $\begin{array}{l}\text { BCVA } \\
\mathrm{n}(\%) \\
\end{array}$ & P-value \\
\hline Less than 1.3 (Blind) & $6(12)$ & $4(8)$ & \multirow{4}{*}{0.001} \\
\hline 1.3-1.1(Severe Visual Impairment) & $21(41)$ & $14(27)$ & \\
\hline 1.0-0.5(Visual Impairment) & $23(45)$ & $31(61)$ & \\
\hline Better than 0.5 (Normal) & 1(2) & $2(4)$ & \\
\hline \multicolumn{4}{|l|}{ Near Visual acuity In Metric } \\
\hline Worse than $2.5 \mathrm{M}$ & $16(31)$ & $13(25)$ & \multirow{3}{*}{0.106} \\
\hline $2.5-1.5 \mathrm{M}$ & $26(51)$ & $24(48)$ & \\
\hline Better than $1.5 \mathrm{M}$ & $9(18)$ & $14(27)$ & \\
\hline Total & 51 & 51 & \\
\hline
\end{tabular}

Distance low vision aids were prescribed to (78\%) among them telescope (65\%) was the most common low vision aids followed by spectacles (14\%) while near low vision aids were prescribed to (94\%) among them spectacle magnifier
(72\%) was most common aids followed by as Hand held magnifier, stand magnifier and pocket magnifier (21\%).

Students (31.5\%) accepted more optical low vision aids for distance followed by unemployed (21\%), farmer (16\%) while for near also students (47\%) accepted more optical aids followed by farmer (14\%), and business (11\%) (Table 4).

Table: 4 Acceptance of low vision device for distance and
near with occupation
\begin{tabular}{|l|c|c|c|}
\hline Occupation & Prescribed & $\begin{array}{c}\text { Accepted for } \\
\text { Distance (\%) }\end{array}$ & $\begin{array}{c}\text { Accepted } \\
\text { for near (\%) }\end{array}$ \\
\hline Farmer & 8 & $3(16)$ & $5(14)$ \\
\hline Business & 8 & $2(10.5)$ & $4(11)$ \\
\hline Students & 20 & $6(31.5)$ & $16(47)$ \\
\hline Teacher & 4 & $2(10.5)$ & $3(9)$ \\
\hline Laborer & 3 & $2(10.5)$ & $2(6)$ \\
\hline Unemployed & 5 & $4(21)$ & $2(6)$ \\
\hline $\begin{array}{l}\text { Others(housewife, } \\
\text { tailor, art and craft) }\end{array}$ & 3 & 0 & $2(6)$ \\
\hline Total & 51 & $19(37)$ & $34(67)$ \\
\hline
\end{tabular}

\section{DISCUSSION}

Biratnagar eye hospital is a tertiary eye hospital with different sub specialty clinics including low vision in Nepal under Nepal Netra Jyoti Sangh (NNJS) in eastern regional eye care programme (EREC-P) that provides eye services to the population in eastern Nepal and northern India along with its satellite clinics. In 2018, 616 low vision assessments was performed, among them 143 were children and 274 devises were dispensed to the low vision patients at $\mathrm{BEH}$ and SCEH (EREC-P). ${ }^{12}$

In this study most of the patients prescribed with the low vision aids according to the improvement of the visual acuity, needs and demand. The majority of patients were male (88\%) similar findings was found in the study done by Shah et al $(74 \%)^{13}$, by Shankar et al $(72 \%)^{9}$, by Khanal et al $(70.71 \%)^{14}$ and by Labh et al $(70 \%){ }^{15}$

The most common age group visiting low vision clinic was of up to 20 yrs. (43\%), followed by 21- 50yrs. (31.5\%), and above 51 yrs. (25.5\%) but the study done by Shankar et al most common age group was of 21 to 50 yrs. (46\%), above 51 yrs. (30\%) and up to 20 yrs. (24\%). ${ }^{9}$ Which indicates low vision occurs in any age group.

Retinal diseases (41\%) were the most common cause of visual impairment which was similar to the study done by Shankar et al $(76 \%)^{9}$ by Khanal et al $(74 \%)^{14}$, by Labh et al $(53 \%)^{15}$ and according to American optometric association. ${ }^{16}$

In this study, the most common occupation was students (38\%) followed by the farmer and business (16\%) while the study done by Labh et al showed farmer (27\%), household work $(18 \%)$ and students (17\%) were the common occupations among the low vision clients. ${ }^{15}$

Spectacle magnifier (72\%) was most common low vision aids prescribed for near followed by stand magnifier and pocket magnifier (21\%), similar findings was found by Labh et al. where spectacle magnifier (55\%), hand held magnifiers 
$(4 \%),{ }^{15}$ and by Shankar et al where spectacle magnifier (44\%) hand held magnifier (20\%)., ${ }^{9} 14$ The reason for accepting the spectacle magnifier was easy handling and cosmetically common as reported by patient. While the study done by Janet Silver et al. where stand magnifier (42\%) was mostly prescribed followed by spectacle magnifier $(38 \%)^{17}$ which was similar in the study done by Khanal et al. where stand magnifiers (34\%), hand held magnifiers (15\%) and spectacle magnifiers $(12 \%){ }^{14}$

Telescope was the most common aid prescribed for distance $(65 \%)$ which was higher to the study done by Khanal et al $(39 \%)^{14}$ and Shankar et al $(38 \%)^{9}$ but the study done by Labh et al showed only (1\%). ${ }^{15}$ Although there was improvement in visual acuity for distance and near with low vision aids the acceptance rate was very low among all profession due to less use, handling problem, expensive.

\section{CONCLUSION}

There are more acceptances of the low vision aids among students for distance and near work compare to other occupation.

\section{RECOMMENDATIONS}

The low vision device should be prescribed according to the education, occupation and needs of the patients. The low vision aids should be delivered in charity for those visually impaired patients who can't afford by themselves. Although there was improvement in vision for distance and near with low vision aids, the acceptance rate was very less so there should be awareness campaign in community regarding low vision and low vision aids. There is a need to increase awareness for female participation for a low vision assessment as there were only (12\%) of females came to low vision clinics.

\section{LIMITATIONS OF THE STUDY}

Small sample size does not permit to apply statistical tools and the data is limited to hospital visited patients.

\section{ACKNOWLEDGMENTS}

We would like to acknowledge all the low vision patients who involved in the study and all staffs of Biratnagar Eye Hospital who have directly or indirectly supported in this study. Similarly we would also like to thanks to Dr. Archana Shrestha and Mr Bijesh Kumar Yadav for their valuable comments on manuscript.

\section{CONFLICT OF INTEREST \\ None}

\section{FINANCIAL DISCLOSURE}

None

\section{REFERENCES}

1. Pizzarello L, Abiose A, Ffytche $T$, Duerksen $R$, Thulasiraj $R$, Taylor $H$, et al. VISION 2020: The Right to Sight: a global initiative to eliminate avoidable blindness. Archives of ophthalmology. 2004;122(4):615-20. DOI: 10.1001/archopht.122.4.615

2. WHO. Blindness and vision impairment 2017 [cited 202010 Jan ]. Available from: https://www.who.int/news-room/fact-sheets/ detail/blindness-and-visual-impairment.

3. NNJS. Low Vision Program 2012 [cited 202010 Jan]. Available from: http://www.nnjs.org.np/index/page/national-low-vision-program.

4. Kempen GI, Ballemans J, Ranchor AV, van Rens GH, Zijlstra GR. The impact of low vision on activities of daily living, symptoms of depression, feelings of anxiety and social support in community-living older adults seeking vision rehabilitation services. Quality of life research. 2012;21(8):1405-11. DOI: 10.1007/s11136-011-0103-5.

5. Scott IU, Smiddy WE, Schiffman J, Feuer WJ, Pappas CJ. Quality of life of low-vision patients and the impact of low-vision services. American journal of ophthalmology. 1999;128(1):54-62. DOI: 10.1016/s00029394(99)00108-7

6. Firouzeh F, Tabatabaee S. Journal of Eye Diseases and Disorders. 2018.

7. Virgili G, Acosta R, Bentley SA, Giacomelli G, Allcock C, Evans JR. Reading aids for adults with low vision. Cochrane Database of Systematic Reviews. 2018(4). DOI:10.1002/14651858. CD003303.pub3.

8. Gnyawali S, Shrestha JB, Bhattarai D, Upadhyay M. Optical needs of students with low vision in integrated schools of Nepal. Optometry and Vision Science. 2012;89(12):1752-6. DOI:10.1097/OPX.0b $013 e 3182772 \mathrm{f3c}$

9. Sudhakar KS, Charanya C, Pandurangan R. Clinical analysis of low vision aids. Journal of Evolution of Medical and Dental Sciences. 2015;4(16):2806-13. DOI: 10.14260/jemds/2015/401

10. Markowitz M. Occupational therapy interventions in low vision rehabilitation. Canadian Journal of Ophthalmology. 2006;41(3):3407. DOI: $10.1139 / 106-020$

11. Chiang PP-C, O'Connor PM, Le Mesurier RT, Keeffe JE. A global survey of low vision service provision. Ophthalmic epidemiology. 2011;18(3):109-21. DOI: 10.3109/09286586.2011.560745

12. EREC-P. Annual Report 2018. Available from: https://www.erecp.org/images/pdf/annual_report_2018.pdf.

13. Shah M, Khan MD. Causes of low vision amongst the low-vision patients attending the Low-Vision Clinic at Khyber Institute of Ophthalmic Medical Sciences (KIOMS), Hayatabad Medical Complex Peshawar, Pakistan. Visual Impairment Research. 2004;6(2-3):89-97. DOI: $10.1080 / 13882350490886627$

14. Khanal S. Profile of low vision population attending low vision clinic in a peripheral eye hospital in Nepal. International Conference of Health Professionals; 2014. DOI: hdl.handle.net/2292/27670

15. Labh R, Adhikari P, Karki P, Singh S, Sitoula R. Characteristic of low vision patients attending an eye hospital in eastern region of Nepal. Nepalese Journal of Ophthalmology. 2015;7(1):33-8. DOI: 10.3126/ nepjoph.v7i1.13164

16. Vaughn W, Maples WC, Hoenes R. The association between vision quality of life and academics as measured by the College of Optometrists in Vision Development Quality of Life questionnaire. Optometry-Journal of the American Optometric Association. 2006;77(3):116-23. DOI: 10.1016/j.optm.2006.01.004

17. Silver J, Gilbert CE, Spoerer P, Foster A. Low vision in east African blind school students: need for optical low vision services. British journal of ophthalmology. 1995;79(9):814-20. DOI: 10.1136/bjo.79.9.814 